\title{
TWO ACCOUNTS OF TRADITIONAL MANGAREVAN COUNTING... AND HOW TO EVALUATE THEM
}

\author{
ANDREA BENDER \\ University of Bergen
}

Time and again over the past centuries, Polynesian numeration systems have attracted considerable attention. Beginning with reports by early missionaries, almost every large ethnographic and linguistic description devoted paragraphs or whole chapters to counting sequences and their application in a range of contexts. Some reports were concerned entirely with the significance of numbers and the art of counting and calculating (e.g., Best 1906, 1907, Biggs 1990, Clark 1839, Clark 1999, Hughes 1982, Large 1902, Lemaître 1985; for examples from Melanesia and Micronesia see Alkire 1970, Benton 1968, Carrier 1981, Harrison and Jackson 1984, Lean 1992, Panoff 1970).

This interest is spurred by several peculiarities of counting in Oceanic languages, which include some of the most regular (mostly decimal) systems with occasionally large power terms, often co-existing with specific counting systems based on diverging counting units (Beller and Bender 2008, Bender and Beller 2006a, 2006b, 2007, Lemaitre 1985). The latter gave rise to speculations regarding a vigesimal nature of these systems (Best 1906, Large 1902), some of which still lingered until recently (Bauer 1997: 289, Hughes 1982).

A particularly fascinating case is the numeration system(s) reported for Mangarevan at the turn of the last century (Buck 1938, Janeau 1908). Its power terms are among the highest in Polynesia, and its specific counting systems are unique in that they have their principally decimal structure superposed with binary steps (Beller and Bender 2008). Information on these systems, however, is scarce and in parts contradictory, and these contradictions cannot be resolved empirically as the specific counting systems had already ceased to be used by the beginning of the last century (Janeau 1908: 21). The goal of this paper is to explore whether it is nonetheless possible to reconstruct sufficient information for an evaluation of two accounts. To this end, advantage can be taken of two facts: (i) that counting systems have structural properties that render some instantiations more plausible than others, and (ii) that the counting systems in Mangarevan can be compared to number systems in related languages and cultures. After all, Mangarevan belongs to the Oceanic branch of the Austronesian language family, which is arguably the best documented and researched language family worldwide (see Greenhill, Blust and Gray 2008, Lynch, Ross and Crowley 2002, Tryon 1995). 


\section{CULTURAL AND LINGUISTIC BACKGROUND}

Mangareva, the main island in the Gambiers, is situated in East Polynesia, approximately $1650 \mathrm{~km}$ southeast of Tahiti. The islands were settled around $950 \mathrm{CE}$ from the west, and served as the starting point for expeditions to the eastward islands of Pitcairn, Henderson and Rapa Nui (Green and Weisler 2002, Kirch, Conte, Sharp et al. 2010, Weisler 2008). The Mangarevan language belongs to the Eastern subgroup of the Nuclear Polynesian languages (Fischer 2001). According to Ethnologue, it was still spoken by about 1600 people in 1987, but this number has dropped to 600 in 2011, and the language is now classified as "in trouble".

Despite its small size, in terms of land area as well as inhabitants, Mangarevan society was highly stratified (Goldman 1970: 150-67) and embedded in extensive exchange relations, both internally, by way of tributes and redistribution (Buck 1938: 207, Kirch 1984: 167), and externally, by way of long-distance exchange with the Marquesas and Society Islands as indicated by stone adzes, and possibly the Tuamotu, Austral and Cook Islands as suggested by similarities in fishhook forms (Green and Weisler 2002: 233, Weisler 2008).

European influence on Mangareva increased with the beginning of proselytisation in 1834 by French padres (Fischer 2001), who also provided the first linguistic descriptions and, concomitantly, the first reports on Mangarevan counting systems. At the same time however, their activities, perhaps unwillingly, also set an end to these specific systems (Janeau 1908: 21). By the end of the 19th century, the Gambier Islands became a French protectorate and part of what was later labelled the Overseas Territory French Polynesia.

Most of the material on traditional counting systems in Mangarevan goes back to French missionaries of the Congrégation des Sacrés-Coeurs de Picpus (Buck 1938: 12, Fischer 2001: 113). The first was Father Honoré Laval, who proselytised in the group from 1834 to 1871 and compiled a dictionary in the 1830s and 1840s, preserved only in Tregear's (1899) English edition. A generation later, Cyprien Lyaousseau incorporated much of Laval's linguistic work into his own lexicon, which then provided a basis for the lexicon compiled mainly by Father Vincent-Ferrier Janeau (Buck 1938: 12, Fischer 2001: 113). Janeau's (1908) lexicon comes with a 200-page grammar that also contains a subsection on numeral adjectives. In addition to the linguistic descriptions by Tregear and Janeau, information on counting is also provided by Laval's (1938) history and Buck's (1938) ethnology of Mangareva. Sir Peter Buck, better known under his Māori name Te Rangi Hiroa, was an anthropologist, doctor, and politician of Polynesian descent and a native speaker of Māori (Beaglehole 1966); he spent 70 days on the 
islands during the Mangareva expedition, organised by the Bernice P. Bishop Museum in 1934 (Buck 1938: 3).

Of those sources, Tregear's dictionary is confined to translations for terms, but does not provide any description of counting sequences, and Laval's history is largely incorporated in Buck's Ethnology of Mangareva, due to the high quality attested to it by Buck (1938: 13). This analysis therefore focuses on the accounts by Janeau (1908) and Buck (1938).

What all of the above-mentioned sources agree upon is the co-existence of different types of counting systems (in this paper tentatively labelled "general" and "mixed systems") and some of their constituents, namely the basic numerals for the numbers from 1 through 9 , and some of the terms for the powers of 10 (see Table 1). But the exact numerical values to which these power terms refer are already controversial, and even more controversial are the structure of and the referents for the specific counting systems.

Table 1. General number words reported for Mangarevan by Tregear (1899), Buck (1938) and Janeau (1908).

\begin{tabular}{|c|c|c|c|}
\hline \multicolumn{4}{|c|}{ Basic numerals (n) } \\
\hline \multicolumn{4}{|c|}{$1=$ ta $i, 2=$ rua, $3=$ toru, $4={ }^{\prime} a, 5=$ rima, $6=$ ono, $7={ }^{\prime} i t u, 8=$ varu, $9=i v a$} \\
\hline \multicolumn{4}{|c|}{ Power numerals $(\mathrm{P})$ according to the account of ... } \\
\hline$P$ & Tregear & Buck & Janeau \\
\hline $10^{1}$ & rogo'uru & rogo 'uru / takau & rogo'uru \\
\hline $2 \cdot 10^{1}$ & takau & rogo'uru / takau & takau \\
\hline $10^{2}$ & rau & rau & rau \\
\hline $10^{3}$ & mano & mano & mano \\
\hline $10^{4}$ & makiu & \multirow{2}{*}{ makiu } & \multirow[t]{2}{*}{ makiu } \\
\hline $2 \cdot 10^{4}$ & makiukiu & & \\
\hline $10^{5}$ & & makiukiu & makiukiu \\
\hline $10^{6}$ & & makorekore & makore \\
\hline $10^{7}$ & & maeaea & makorekore \\
\hline $10^{8}$ & & & tini \\
\hline $10^{9}$ & & & maeaea \\
\hline infinite & $\begin{array}{c}\text { makorekore } \\
\text { tini }\end{array}$ & $\begin{array}{l}\text { tini(tini) } \\
\text { mokiukiu }\end{array}$ & \\
\hline
\end{tabular}

Note: Spelling according to Buck (1938); terms that refer to pair-counting $\left(2 \cdot 10^{\mathrm{x}}\right)$ are shaded. 


\section{BUCK'S ACCOUNT}

In his Ethnology of Mangareva, Buck (1938) devotes two pages (pp. 416-18) to the "system of counting". In quoting Laval (1938), he distinguishes five methods of counting: a general counting system, a pair counting system and a mixed system in three variants. ${ }^{1}$ As the pair counting system differs only in one aspect from the general system, the two are merged in the following description.

\section{The general (and pair) counting system.}

The general manner of counting in Mangarevan employed the basic numerals for the numbers 1 through 9 and terms for the powers of 10 up to $10^{7}$, as given in Table 1. These numerals constitute a decimal and (unlike English) perfectly regular system, as was widespread throughout Polynesia (Bender and Beller 2006a). The composition of number expressions in this system is polynomial:

$$
\mathrm{N}_{\text {gen }}=\left[\mathrm{n} \mathrm{P}_{10^{7}}\right]+\ldots+\left[\mathrm{nP}_{10^{2}}\right]+\left[\mathrm{n} \mathrm{P}_{10^{1}}\right]+[\mathrm{n}]
$$

with $\mathrm{n} \in\{1, \ldots, 9\}$ and $\mathrm{P}=$ power numeral (according to Table 1).

$N$ in this formula represents any number expression in the counting sequence, $n$ the basic numerals for 1 through 9 , and $P$ the power terms, with the subscript numbers indicating the power level. Square brackets indicate that terms are optional. The only (minor) irregularity is that two alternate terms could be used to denote 10: rogo 'uru and takau. For illustration of the formula, consider the following instance:

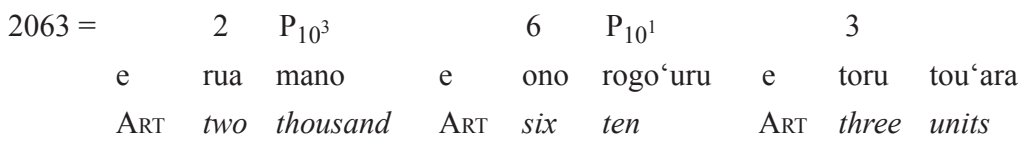

(Please note that, in addition to the numerical constituents included in the formula, this expression also encompasses the indefinite article (ART) and a term indicating a unit (tou 'ara) that is added to ten or to a multiple of ten.)

This system was used for counting in general, and in particular all those items for which the object-specific counting system did not apply, such as men, houses, boats, stars, etc. (Buck 1938: 417).

The pair counting system used the exact same numerals and power terms as the general system, with the exception that items were counted in pairs (tauga). This system of pair counting was used for breadfruits and other fruits (Buck 1938: 417). The expression: 


\begin{tabular}{rlllllll}
$2063=$ & 2 & $\mathrm{P}_{10^{3}}$ & & 6 & $\mathrm{P}_{10^{1}}$ & \multicolumn{2}{c}{3} \\
& $\mathrm{e}$ & rua & mano & $\mathrm{e}$ & ono rogo'uru & $\mathrm{e}$ & toru tauga \\
& ART & two & thousand & ART & six & ten & ART three units
\end{tabular}

therefore differs from the one above only by usage of the term tauga (rather than tou'ara), which implies an object-specific counting unit. That, in the case of breadfruits, this unit contained a pair of fruits is something one needed to know in order to assess the correct absolute number of items, namely 4126 breadfruits.

The mixed counting system.

The mixed system contrasts more sharply with the general counting system in that it mixes two different bases by superposing binary steps on the decimal structure (cf. Table 2). The primary counting unit tauga was counted with numerals from 1 through $9 ; 10$ tanga then equalled 1 takau, 2 takau= 1 paua, 2 paua $=1$ tataua , and 2 tataua $=1$ varu. This latter unit was then again counted with numerals from 1 through 9 (up to iva varu). The composition of number expressions in this sequence was thus patterned after the following rule:

$\mathrm{N}_{\text {mix }}=\left[\mathrm{n} \mathrm{U}_{80}\right]+\left[\mathrm{U}_{40}\right]+\left[\mathrm{U}_{20}\right]+\left[\mathrm{U}_{10}\right]+\left[\mathrm{n} \mathrm{U}_{1}\right]$

with $n \in\{1, \ldots, 9\}$ (according to Table 1 ) and $U=$ unit term (according to Table 2 [over the page]).

For illustration of the formula, consider the following instance:

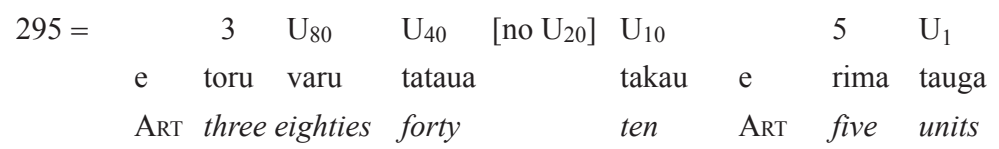

The mixed system occurred in one of three variants, which differed solely in the size of the counting unit. Depending on the object counted, the counting unit tauga took a value of 1 (in the case of turtles), of 2 (in the case of fish), or of 4 (in the case of coconuts) (Buck 1938: 417). Laval (1938: 211) mentions a fourth variant, restricted to counting octopuses, in which tauga took a value of 8 . Assuming that in the instance above coconuts were counted, the expression for 295 would then refer to 295 units of 4 each $=1180$ single coconuts.

The largest possible number to be composed in this system is 9 varu + tataua + paua + takau +9 tang $a=720+40+20+10+9=799$ tanga , which equals absolute numbers of 799, 1598 and 3196 (and perhaps 6392), respectively. 

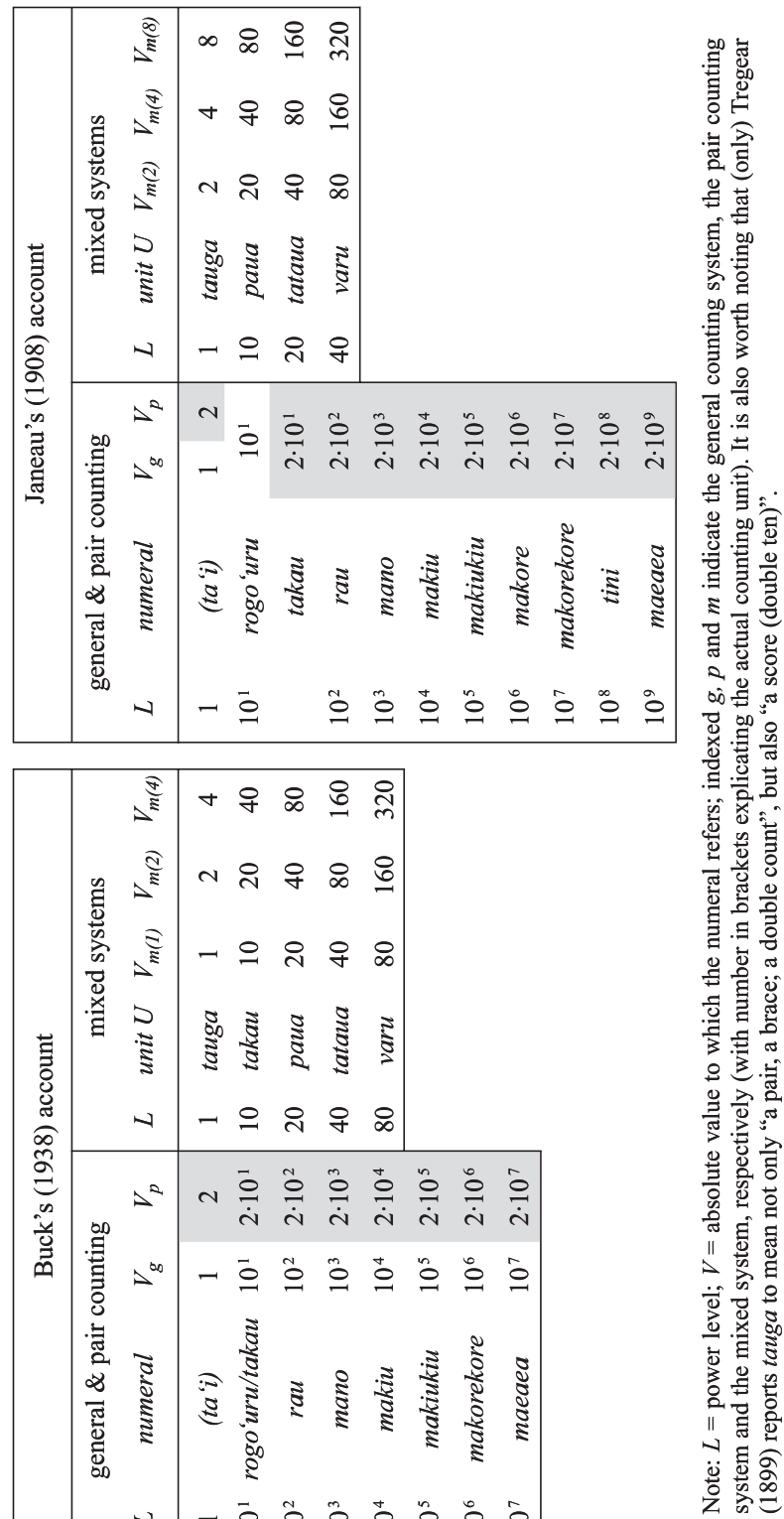


\section{JANEAU'S ACCOUNT}

Section 3 of Chapter III in Janeau's Essai de grammaire (1908: 18-21) is devoted to the numeral adjectives, but also provides information on counting manners. Janeau distinguishes two principle manners of counting, based on how the units of 10s are denoted: one in which they are denoted takau, and one in which they are denoted paua. The former, occurring in two variants, corresponds to the general counting systems, and the latter, occurring in three variants, corresponds to the mixed system. As emphasised by Janeau, in all of these variants, it was always the objects that dictated which manner of counting was required.

The general (and pair) counting system.

According to Janeau, the most general manner of counting in Mangarevan employed the basic numerals for the numbers 1 through 10 and terms for the powers of 10 up to $10^{9}$, as given in Table 1 . In contrast to other accounts, however, the power terms reported by Janeau do not refer to the pure powers of 10, but to 2 times these powers: 2 rogo 'uru are reported to equal 1 takau (20), 10 takau = $1 \mathrm{rau}$ (200), $10 \mathrm{rau}=1$ mano (2000) and so on. The composition of number expressions in this system thus contains an irregular step:

$\mathrm{N}_{\text {gen }}=\left(\left[\mathrm{n} \mathrm{P}_{10^{9}}\right]+\ldots+\left[\mathrm{n} \mathrm{P}_{10^{2}}\right]+\left[\mathrm{n} \mathrm{P}_{10^{1}}\right]\right)_{[2]}+[10]+[\mathrm{n}]$

with $\mathrm{n} \in\{1, \ldots, 9\}$ and $\mathrm{P}=$ power numeral (according to Table 1); the indexed number 2 in square brackets indicates the new counting unit, which, however, remained implicit.

Janeau himself did not provide concrete examples for how a compound number expression in this system would look, but according to his description (and the convention of adding an indefinite article to each constituent, as indicated by Buck) the number 2063 from above should be expressed here as follows:

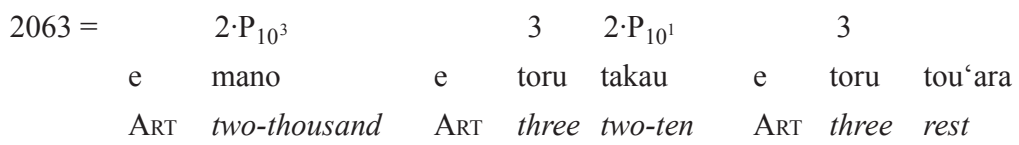

This manner of general counting occurred in one of two variants: one variant in which items were counted one by one (tipau tahi), and one variant in which they were counted in pairs (tipau rua). Janeau's list of singly counted objects includes people, game, reptiles, birds, insects, shells, land, trees, boats, cloth, pearls, stars, etc., while the other group includes breadfruits, pandanus leaves used for thatching, agricultural tools, sugar cane, etc. 
In pair counting (tipau rua), a single item was called tou 'ara (i.e., rest), and if a pair of 10s (takau) was not complete, the single 10 was called rogo 'uru tou'ara.

The mixed counting system.

The second counting manner employed the same basic numerals for the numbers 1 through 9 as the general system, albeit combined with tauga which, again, indicates a diverging counting unit. The units of 10 s were denoted paua, with 2 rogo 'uru $=1$ paua, 2 paua $=1$ tataua, and 2 tataua $=1$ varu (cf. Table 2). As in Buck's (1938) account, but to a lesser extent, these specific terms introduced binary steps into an otherwise decimal system. The unit varu was then again counted with numerals from 1 through 10 (up to rogo 'uru varu). Single items were called tou 'ara (rest), and if a tataua was not complete, the single paua was called paua tou'ara. The composition of number expressions in this sequence was thus patterned after the following rule:

$$
\mathrm{N}_{\text {mix }}=\left[\mathrm{n} \mathrm{U}_{40}\right]+\left[\mathrm{U}_{20}\right]+\left[\mathrm{U}_{10} \mathrm{R}\right]+\left[\mathrm{n} \mathrm{U}_{1}\right]+[\mathrm{R}]
$$

with $\mathrm{n} \in\{1, \ldots, 9\}$ (according to Table 1), $\mathrm{U}=$ unit term (according to Table 2), and $\mathrm{R}=$ rest (tou'ara).

Again, no examples are provided by Janeau, but according to his description, the number 295 (taken to illustrate Buck's account above) should be expressed here as follows:

\begin{tabular}{|c|c|c|c|c|c|c|}
\hline $295=$ & 7 & $\mathrm{U}_{40}$ & {$\left[\right.$ no $\left.U_{20}\right]$} & $\mathrm{U}_{10}$ & & 5 \\
\hline e & hitu & varu & & paua & e & rima \\
\hline ART & seven & forties & & ten & ART & five \\
\hline
\end{tabular}

The mixed system occurred in one of three variants, which differed solely in the size of the counting unit (Janeau 1908: 20): Depending on the object counted, the counting unit tauga took a value of 2 (as in pair counting and for the objects described there), of 4 (in the case of, for example, ripe breadfruits and octopuses), or of 8 (in the case of the first breadfruits and octopuses of the season).

The largest possible number to be composed in this system is 10 varu $=400$ tauga, which equals absolute numbers of 800,1600 and 3200, respectively. 


\section{COMPARISON AND ASSESSMENT}

Although, at first glance, the systems described by Buck (1938) and Janeau (1908) may appear rather similar, they do diverge in important aspects. The general (and pair) counting systems differ with regard to (i) the number and (ii) the value of power terms, (iii) the relation of general and pair counting systems, and of rogo 'uru and takau in particular; and, the mixed systems differ with regard to (iv) the number of binary steps, (v) the value that the counting unit tauga could take, and (vi) the objects that were counted in these manners.

It will be impossible to resolve with ultimate certainty which of these accounts (or whether, indeed, any of these accounts) is correct. They were written at different times, and counting systems may simply have changed in between. And yet, some of the details given by the authors - in combination with what is known about Polynesian counting systems more generally-may help to shed light on this question.

All Polynesian languages contained general counting systems that were regular and decimal, with terms for large powers of 10. Most Polynesian languages also contained, in pre-European times, distinct counting systems that were restricted to specific objects and based on diverging counting units, typically involving one or more of the factors 2, 4, 10 and 20, all of which are even numbers (Bender and Beller 2006a: 41, 2006b: 369). This is in line with the concern for symmetry as well as large numbers, attested to for various Polynesian groups and particularly the highly stratified societies (Bender and Beller 2006a, 2007; Best 1906; Elbert 1988: 186, 198; Elbert and Pukui 1979: 161; Hanson 2004; Henry 1928: 323; Hughes 1982; Lemaître 1985). Differences across languages basically concern the number and value of power terms, the value of the specific counting units, and the objects specifically counted (Bender and Beller 2006a, 2006b).

Against this background, the differences in the accounts of Buck (1938) and Janeau (1908) regarding the range of power terms, the value of counting units and the specific objects cannot be resolved. Variation in these properties has emerged recurrently, and likely in adaptation to cultural and or environmental requirements. For the other differences, however, an evaluation can be attempted.

Both Buck and Janeau describe a general system (in two variants), which they clearly distinguish from three mixed systems used for counting specific objects only. However, the general system in Buck's account is perfectly regular and decimal; it is supplemented by a pair counting system, which simply duplicates the general system; and it is set apart from a type of system in which the decimal structure is superposed with binary steps (see Table 2). In contrast, the general system as described by Janeau already entails a 
binary step, namely from rogo 'uru to takau. From 20 onwards, all number expressions purportedly refer to pairs of items, even those in the system for counting singly (tipau tahi). Still, this system is said to be supplemented by a pair counting system (tipau rua), but how exactly this was operationalised is not explicated. The regularity of both the general and the pair counting system in Buck's account — as opposed to the opaque and incoherent description by Janeau - thus supports the former.

When we turn to the mixed systems, the most conspicuous difference between the two accounts concerns the number of binary steps, of which there is one more in Buck's account (where takau is inserted between tauga and paua). While there is nothing about binary steps themselves to suggest which number might be more plausible, the terms are suggestive. First, of all systems in Janeau's account, it is the mixed system that does not comprise the term takau - in stark contrast to a range of Polynesian languages, in which takau is virtually indicative (and sometimes even exclusively so) of a mixed system (Bender and Beller 2006a, 2006b). And second, the largest specific term in the mixed system, concordantly reported by both, is varu, although denoting 40 units in Janeau's account, and 80 in Buck's account. As varu also refers to 8 in the basic sequence (see Table 1), it seems more plausible that varu should refer to 80 units, thus favouring, again, Buck's account over Janeau's account.

Finally, a quite minor, yet perhaps telling detail is that the largest power term in the mixed systems is reported as 9 varu by Buck, but as 10 varu by Janeau. The latter would be a violation of the polynomial schema according to which almost all number expressions in almost all Polynesian languages are composed (Beller and Bender 2008, Bender and Beller 2006a, 2006b), namely using distinct terms for each new power level, whereas in European languages such as English or French, such violations do occur (e.g., in "ten thousand"). Even if this mistake were a simple slip of the pen, it is in line with the overall assessment.

$$
* * *
$$

In conclusion, the system described by Buck (1938) appears, by and large, to be more meticulous and reliable, at least with regard to those properties for which one may venture an evaluation, informed by and based on crosscultural and cross-linguistic data. This approach does not solve all the puzzles offered by historical accounts of Mangarevan counting systems. How far power terms actually reached, for instance, or what these large numbers could have been used for, may never be fathomable (see Elbert and Pukui 1979: 160f.). Other issues for investigation, such as the possible advantages offered by a counting system with binary steps, require different approaches 
altogether (see Bender and Beller, MS.; Bender, Schlimm and Beller, MS.). But the approach presented here does enable the evaluation of the relative plausibility of diverging accounts, and offers tentative resolutions for some of the contradictory evidence with which we are often confronted.

\section{ACKNOWLEDGEMENTS}

This work was supported by a Heisenberg Fellowship from the Deutsche Forschungsgemeinschaft DFG (Be 2451/8-2). I am indebted to Susanne Bubser for her assistance with the sources and to Sieghard Beller for inspiration and discussions on earlier versions of this paper.

\section{NOTE}

1. Notably, Laval himself described four variants of the mixed system (1938:211-13).

\section{REFERENCES}

Alkire, William, 1970. Systems of measurement on Woleai Atoll, Caroline Islands. Anthropos 65: 1-73.

Bauer, Winifred (with William Parker, Te Kareongawai Evans and Te Aroha Noti Teepa), 1997. The Reed Reference Grammar of Maori. Auckland: Reed Books.

Beaglehole, Ermest, 1966. Buck, Sir Peter Henry (Te Rangihiroa), K.C.M.G., D.S.O. In A.H. McLintock (ed.), An Encyclopaedia of New Zealand. [information retrieved from: Te Ara - the Encyclopedia of New Zealand, updated 27-Oct-11; URL: http://www.TeAra.govt.nz/en/1966/buck-sir-peter-henry]

Beller, Sieghard and Andrea Bender, 2008. The limits of counting: Numerical cognition between evolution and culture. Science 319: 213-15.

Bender, Andrea and Sieghard Beller, 2006a. "Fanciful" or genuine? Bases and high numerals in Polynesian number systems. Journal of the Polynesian Society 115: 7-46.

2006b. Numeral classifiers and counting systems in Polynesian and Micronesian languages: Common roots and cultural adaptations. Oceanic Linguistics 45: 380-403.

2007. Counting in Tongan: The traditional number systems and their cognitive implications. Journal of Cognition and Culture 7: 213-39.

_ in press. Mangarevan invention of binary steps for easier calculation. Proceedings of the National Academy of Sciences of the United States of America.

Bender, Andrea, Dirk Schlimm and Sieghard Beller MS. The cognitive advantages of counting specifically: A representational analysis of verbal numeration systems in Oceanic languages. Submitted for publication to Topics in Cognitive Science, Special issue, "Exploring Cognitive Diversity: Anthropological Perspectives on Cognition".

Benton, Richard A., 1968. Numeral and attributive classifiers in Trukese. Oceanic Linguistics VII (2): 104-46. 
Best, Elsdon, 1906. Maori numeration: Some account of the single, binary, and semivigesimal systems of numeration formerly employed by the Maori. Transactions and Proceedings of the New Zealand Institute 39: 150-80. 1907. Maori numeration. Journal of the Polynesian Society 16: 94-98.

Biggs, Bruce, 1990. Extraordinary eight. In J.H.C.S. Davidson, K.K.T. Mara and H. Cordell (eds), Pacific Island Languages: Essays in Honour of G.B. Milner. London: School of Oriental and African Studies, University of London, and Honolulu: University of Hawaii Press, pp. 29-39.

Buck, Peter [Te Rangi Hiroa], 1938. Ethnology of Mangareva. Bernice P. Bishop. Museum Bulletin 157. Honolulu.

Carrier, Achsah, 1981. Counting and calculation on Ponam Island. Journal of the Polynesian Society 90 (4): 465-79.

Clark, E.W., 1839. Hawaiian method of computation. Hawaiian Spectator 2: 91-94.

Clark, Ross, 1999. Proto-Polynesian numerals. In E. Zeitoun and P.J-K. Li (eds), Selected Papers from the Eighth International Conference on Austronesian Linguistics. Taipei: Academia Sinica, pp. 195-204.

Elbert, Samuel H., 1988. Echo of a Culture: A Grammar of Rennell and Bellona. Oceanic Linguistics Special Publications 22. Honolulu: University of Hawai'i Press.

Elbert, Samuel H. and Mary Kawena Pukui, 1979. Hawaiian Grammar. Honolulu: University of Hawai' $i$ Press.

Fischer, Steven Roger, 2001. Mangarevan doublets: Preliminary evidence for ProtoSoutheastern Polynesian. Oceanic Linguistics 40: 112-24.

Goldman, Irving, 1970. Ancient Polynesian Society. Chicago: University of Chicago Press.

Green, R.C. and Marshall I. Weisler, 2002. The Mangareva sequence and dating of the geographic expansion into Southeast Polynesia. Asian Perspectives 41: 213-41.

Greenhill, Simon J., Robert Blust and Russell D. Gray, 2008. The Austronesian basic vocabulary database: From bioinformatics to lexomics. Evolutionary Bioinformatics 4: 271-83.

Hanson, F. Allan, 2004. Symmetry for itself, for culture, and for practice. In D.K. Washburn (ed.), Embedded Symmetries, Natural and Cultural. Albuquerque: University of New Mexico Press in conjunction with the Amerind Foundation, pp. 145-59.

Harrison, Sheldon and Frederick H. Jackson, 1984. Higher numerals in several Micronesian languages. In B.W. Bender (ed.), Studies in Micronesian Linguistics. Pacific Linguistics, Series C-80. Canberra: Australian National University, pp. 59-78.

Henry, Teuira, 1928. Ancient Tahiti. Bernice P. Bishop Museum Bulletin 48. Honolulu, pp. 323-35.

Hughes, Barnabas, 1982. Hawaiian number systems. Mathematics Teacher 75: 253-56. [Janeau, Vincent-Ferrier], 1908. Essai de grammaire de la langue des îsles Gambier ou Mangaréva par les missionaires catholiques de cet archipel, membres de la Congrégation des Sacrés-Coeurs de Picpus. Braine-le-Comte, Belgium: Imprimerie Zech et Fils. 
Kirch, Patrick V., 1984. The Evolution of the Polynesian Chiefdoms. Cambridge: Cambridge University Press.

Kirch, Patrick V., Eric Conte, Warren Sharp and Cordelia Nickelsen, 2010. The Onemea Site (Taravai Island, Mangareva) and the human colonization of Southeastern Polynesia. Archaeology in Oceania 45: 66-79.

Large, J.J., 1902. The vigesimal system of enumeration. Journal of the Polynesian Society 11: 260-61.

Laval, P[ère] Honoré, 1938. Mangaréva: L'histoire ancienne d'un peuple Polynésien. Braine-le-Comte / Paris: Maison des Pères des Sacrés-Coeurs / Librairie Orientale Paul Geuthner.

Lean, Glendon A., 1992. Counting Systems of Papua New Guinea. Unpublished manuscript. Available at http://www.uog.ac.pg/glec/thesis/thesis.htm (Glen Lean Ethnomathematics Centre, Lae.)

Lemaître, Yves, 1985. Les systèmes de numération en Polynésie orientale. Journal de la Société des Océanistes 80: 3-13.

Lynch, John, Malcolm Ross and Terry Crowley, 2002. The Oceanic Languages. Richmond: Curzon.

Panoff, Michel, 1970. Father arithmetic: Numeration and counting in New Britain. Ethnology, 9: 358-65.

Tregear, Edward, 1899. Mangareva Dictionary, Gambier Islands. Wellington: John MacKay, Government Printer.

Tryon, Darrell T. (ed.), 1995. Comparative Austronesian Dictionary: An Introduction to Austronesian Studies. 4 volumes. Berlin, New York: Mouton de Gruyter.

Weisler, Marshall I., 2008. Tracking ancient routes across Polynesian seascape with basalt artifact geochemistry. In B. David and J. Thomas (eds.), Handbook of Landscape Archaeology. Walnut Creek: Left Coast Press, pp. 536-43.

\begin{abstract}
Among the traditional counting systems in Polynesian languages, those conveyed for Mangarevan provide particularly interesting and challenging cases. Accounting for their peculiarities presupposes accurate descriptions of their structure and key properties. Unfortunately, however, available descriptions are contradictory and partly incoherent. This paper attempts to resolve some of these contradictions by analysing and contrasting two accounts of Mangarevan counting and placing them in a cross-linguistic context.
\end{abstract}

Keywords: Mangareva, numeration systems, specific counting, power terms, Polynesian languages 
